\section{Ulysses treads a lonely path}

\section{London}

AfTER a successful launch and deployment from the space shuttle Discovery on 6 October, the Ulysses solar probe is now speeding towards Jupiter on the first leg of a five-year voyage to fly over both poles of the Sun. The mission is still a collaboration between the European Space Agency (ESA) and the US National Aeronautics and Space Administration (NASA), even though a bitter taste remains from NASA's sudden cancellation of a companion probe to Ulysses in 1981.

Ulysses will be the first spaceprobe to fly over the Sun's poles, taking measurements of the solar wind (see Nature 347, 439; 4 October 1990), its associated magnetic field patterns and the Sun's output of X-rays, radio and plasma waves. Until now, all solar observations have been made from the same ecliptic plane in which the Earth orbits the Sun. Spacecraft launched from Earth are flung out in this plane automatically, because of the Earth's own movement, and there is no launch vehicle sufficiently powerful to put Ulysses directly into a solar polar orbit. To overcome the problem, Ulysses will make a 'gravity assist manoeuvre' around Jupiter in February 1992 (similar to those made by Voyager 2 during its tour of the outer planets), stealing energy from the planet to send it in a southern trajectory back towards the Sun, culminating in a south polar flypast in the summer of 1994. Ulysses will then swing round the Sun, flying over the north pole one year later.

Richard Marsden, ESA deputy project scientist, is enthusiastic about the complement of instruments flying on Ulysses, picking out the measurement of heavy element ions in the solar wind and the detection of cosmic rays from outside the Solar System as particularly promising experiments. But Marsden says the loss of the NASA probe will cause "certain problems in interpreting the data".

In the original plan, two probes would have flown past opposite poles simultaneously, allowing both to be studied at the same time with a core payload of instruments shared by the two craft. Ulysses will observe both poles, but it will now be difficult to tell if observed differences between the north and south poles are due to inherent differences between the two or to variation in the Sun's activity in time. Observations using an X-ray/extreme ultraviolet telescope and of the Sun's corona were to be made from the companion craft and are now lost completely.

Joan Johnson-Freese, from the Center for Space Policy and Law at the University of Central Florida, says that NASA's contribution to what was then known as the International Solar Polar Mission (ISPM) was the victim of a "unique set of circum- stances". In 1981, President Ronald Reagan's new administration was making deep cuts throughout the US budget, while NASA was stripping resources from other space programmes to meet the space shuttle's ballooning costs. NASA was told that one project from the ISPM, the Hubble Space Telescope or the Galileo Jupiter probe, would have to be cut.

But it was not NASA's cancellation of the second ISPM probe that angered ESA officials so much as the lack of consultation before the announcement. JohnsonFreese says ESA and other collaborators were left asking themselves the question: "what good is a memorandum of understanding?", if US budgetary squeezes can jeopardize collaborative projects. She says this has coloured recent negotiations on collaborations such as the planned Freedom space station and the Earth Observing System remote-sensing network.

Ian Pryke, head of the ESA office in Washington, maintains that ESA's relations with NASA are now back on course after the "low point" of the early 1980s. But ESA has little choice but to collaborate with NASA on expensive space science projects, given the limits of its own science budget. Ironically, Willis Meeks, NASA project manager for Ulysses, says the savings achieved through the cancellation were "probably nil". NASA is still paying for two-thirds of the $\$ 750$-million mission, supplying the expensive shuttle launch, the booster rocket to power Ulysses towards Jupiter and use of its Deep Space Network. Any savings have been dwarfed by cost overruns because of reGENETIC ENGINEERING

\section{Glasnost for UK release information}

\section{London}

BowiNg to pressure from environmentalist groups and members of the House of Lords, the UK government is to amend the Environmental Protection Bill so as to ensure public access to information on proposed releases of genetically engineered organisms. The government had originally argued that clauses on public access were not needed because the Environment Secretary already has the power to make this information public.

The new clauses propose public registers containing applications for consents to release, supporting information supplied with these applications, and any advice given to the Environment Secretary by the new independent Advisory Committee on Releases to the Environment (ACRE). Some information may be withheld if the Environment Secretary decides that this would undermine national security, provoke sabotage by extremist groups which would present an environ- peated launch delays.

The original launch date was February 1983, but NASA was forced to delay by two years in 1981, to allow that year's budget to balance (despite the fact that this increased overall cost), and the 1986 Challenger disaster caused further setbacks.

Johnson-Freese says ISPM was the victim of the US budgetary system, where government spending is determined year by year. This means that agencies such as NASA and the National Science Foundation (NSF) cannot guarantee a continued level of funding for their side of agreed international 'big science' projects.

D. Allan Bromley, science adviser to the US president, has stressed the foreign perception of the United States as an "unreliable partner" in many of his speeches, and called for "something more like treaty arrangements" to govern international projects.

One solution would be longer-term earmarking of funds for important collaborations. But Dick Malow, a member of staff of the House of Representatives appropriations subcommittee that handles the NASA and NSF budgets, says the US presidential system of government, where members of the House of Representatives are re-elected every two years, precludes this change. Other congressional staff turn criticism of the US budgetary system back on NASA, claiming that NASA has repeatedly given low cost estimates for 'new start' projects and then expected Congress to pay for cost overruns. The same staff say that NASA is still guilty of a lack of realism, asking for an annual budget growth of 15 per cent in real terms in the face of the huge current US budget deficit.

Peter Aldhous

mental hazard, or breach commercial confidentiality. But in commercially sensitive cases, the name and address of the applicant, a description of the organism and the purpose of the release, and the results of any assessment of the environmental risks posed must still be included.

Julian Kinderlerer, from the University of Sheffield, a member of ACRE who has been advising the opposition Labour party on the release of engineered organisms, says he is "thrilled" by the amendments, and surprised at how far the government has gone. The publication of ACRE's advice is particularly significant, he says, because it puts the onus on the Environment Secretary to justify any decisions that go against ACRE's advice. A further amendment makes ACRE a statutory committee, so that a decision of parliament would be needed to abolish it or alter its status. The new amendments will be discussed in the House of Lords next week, at the bill's report stage. Peter Aldhous 